\title{
A phase II trial of induction chemotherapy and chemo-IMRT for head and neck squamous cell cancers at risk of bilateral nodal spread: the application of a bilateral superficial lobe parotid-sparing IMRT technique and
} treatment outcomes

\begin{abstract}
A B Miah ${ }^{1}$, U Schick ${ }^{1}$, S A Bhide ${ }^{1,2}$, M-T Guerrero-Urbano ${ }^{1,2}, \mathrm{C} \mathrm{H} \mathrm{Clark}^{2,3}$, A M Bidmead ${ }^{2,3}$, S Bodla ${ }^{4}$, L Del Rosario ${ }^{1}$, K Thway ${ }^{5}$, P Wilson ${ }^{6}, \mathrm{~K}$ L Newbold ${ }^{1}, \mathrm{~K}$ J Harrington ${ }^{1,2,7}$ and C M Nutting ${ }^{\star 1,2,7}$

${ }^{1}$ Head and Neck Unit, The Royal Marsden NHS Foundation Trust, London (and Surrey), UK; ${ }^{2}$ The Institute of Cancer Research, London, UK; ${ }^{3}$ Department of Physics, The Royal Marsden NHS Foundation Trust, London, UK; ${ }^{4}$ Department of Statistics, The Royal Marsden NHS Foundation Trust, London, UK; ${ }^{5}$ Department of Histopathology, The Royal Marsden NHS Foundation Trust, London, UK and 'Department of Histopathology, St George's Healthcare, London, UK
\end{abstract}

Purpose: To determine the feasibility of induction chemotherapy and chemo-IMRT in head and neck squamous cell cancers at risk of bilateral nodal spread (midline tumours) and to evaluate whether bilateral superficial lobe parotid-sparing IMRT can reduce the incidence of $\geqslant G 2$ subjective xerostomia.

Methods: Patients with midline tumours were enrolled to a phase $\|$ trial to receive induction platinum/5-fluorouracil and concomitant platinum with combined superficial lobe parotid-sparing IMRT. The primary site and involved nodal levels received $65 \mathrm{~Gy}$ in 30 fractions ( $f$ ) and at risk nodal levels, $54 \mathrm{~Gy} / 30 f$. Incidence of $\geqslant G 2$ subjective xerostomia was defined as the primary endpoint. Secondary endpoints included incidences of acute and late toxicities and survival outcomes dependent on human papilloma virus (HPV) status.

Results: One hundred and twenty patients with midline cancers completed treatment between December 2005 and May 2010 with median follow-up of 50 months. Incidences of $\geqslant G 2$ acute toxicities were: dysphagia $75 \%$; xerostomia $65 \%$; mucositis $86 \%$; pain $83 \%$; and fatigue 64\%. At 12 months, $\geqslant$ G2 subjective xerostomia was observed in $21 \%$ (17\% in HPV + ve). Two-year locoregional progression-free survival (PFS) was 90.7\% (95\% Cl: 85.2-96.2). According to HPV status, there was a significant difference for 2-year loco-regional PFS, 76.8\% (HPV-negative) vs 98.6\% (HPV-positive), $P=0.001$. 2-year overall survival was 93\% for HPVpositive compared with $52 \%$ for HPV-negative cases, $P<0.001$.

Conclusions: Sequential chemotherapy/chemo-IMRT for midline tumours is feasible, with excellent survival outcomes. At 1 year, $21 \%$ experience $\geqslant G 2$ subjective xerostomia. Two-year survival outcomes differ significantly between HPV-positive and HPVnegative disease, suggesting development of different treatment schedules for the different disease entities.

*Correspondence: Professor CM Nutting; E-mail: chris.nutting@rmh.nhs.uk

${ }^{7} \mathrm{KJH}$ and $\mathrm{CMN}$ are joint senior authors.

Received 18 June 2014; revised 7 September 2014; accepted 4 October 2014; published online 4 December 2014 (c) 2015 Cancer Research UK. All rights reserved 0007-0920/15 
Oropharyngeal and hypopharyngeal cancers account for nearly 2800 new cases of cancer annually in the UK (National Cancer Intelligence Network, 2008). Radical chemoradiation is the main non-surgical treatment option for locally advanced head and neck squamous cell cancers (HNSCC). Concomitant cisplatin with radiotherapy for locally advanced squamous cell cancer of the oropharynx can achieve loco-regional failure-free rates of $75-80 \%$ at 2 years. Induction chemotherapy has been incorporated into current practice in many institutions using cisplatin and 5-fluorouracil (PF) or PF plus docetaxel (Posner et al, 2007; Vermorken et al, 2007; Bhide et al, 2008).

Although tobacco and alcohol consumption remain the main risk factors for the development of HNSCC, a causal link between human papilloma virus (HPV) and a subgroup of HNSCC has been clearly established (Gillison, 2004; Mehanna et al, 2010). There is an increasing incidence of HPV-positive oropharyngeal cancers and it is predicted to continue to increase.

Xerostomia is the most commonly reported late toxicity which can effect speech, swallow and significantly impact on quality of life (Pow et al, 2006). Tumours at risk of bilateral nodal spread have been defined as 'midline' tumours in this paper. Treatment of midline squamous cell carcinomas of the head and neck, for example, base of tongue tumours and those with bilateral neck disease includes irradiation of the bilateral parapharyngeal spaces. This can result in a high dose to the deep lobe of the parotid glands. This is in contrast to patients treated in the PARSPORT Trial whereby sparing of the entire contralateral parotid gland was achieved, as the contralateral parapharyngeal space was spared (Nutting et al, 2011). The purpose of this prospective study was to report on the survival outcomes associated with HPV status and determine whether sparing of the superficial lobes of both parotid glands using IMRT can reduce xerostomia levels similar to or below that seen with unilateral parotid gland sparing radiotherapy (PARSPORT Trial).

\section{MATERIALS AND METHODS}

Study objectives/patient eligibility. Patients diagnosed with histologically confirmed locally advanced HNSCC arising from the oropharynx or hypopharynx with high risk of bilateral parapharyngeal space involvement were eligible. Patients $<18$ years old or with a previous malignancy other than nonmelanomatous skin cancer were excluded. Pre-treatment evaluations comprised history and examination, examination under anaesthesia, biopsy, dental assessment, haematological and biochemical parameters and computed tomography (CT) scan of the head, neck and chest. Disease was staged by the 1997 American Joint Committee on Cancer Staging (Patel and Shah, 2005). Patients were required to attend for regular follow-up for subjective and objective assessments. All patients signed a written informed consent and the study was approved by the institutional research and ethics committee (Royal Marsden Hospital CCR 2588, clinical trials registration number: NCT02149602).

The primary objective was to determine the incidence of high-grade $(\geqslant \mathrm{G} 2)$ xerostomia at 1 year using the LENTSOMA scoring scale. Secondary objectives included 2-year loco-regional progression-free survival (LRPFS), progression-free survival (PFS) and overall survival (OS) associated with HPV status and the incidence of acute and other late radiation toxicities. LRPFS was defined as the time from the diagnosis to loco-regional recurrence or progressive disease (PD) as defined by RECIST criteria, DFS was defined as time from diagnosis to local and or distant relapse, OS (defined as the time from the randomisation to death from any cause).

Study design. This was a prospective observational study of 120 patients to determine the treatment outcomes following chemoradiation for midline oropharyngeal and hypopharyngeal cancers and the incidence of grade 2 or more xerostomia using the LENTSOMA scoring scale with an alternative parotid-sparing IMRT technique. The xerostomia data were compared with the experimental arm of the PARSPORT Trial which represented an alternative parotid-sparing technique. The sample size in the PARSPORT trial was 42 patients in each arm, therefore for similar sample size, the aim was to recruit 42 patients into this phase II trial. The sample size was extended to 120 patients with a substantial amendment to take into account a larger cohort of patients to report toxicities and survival outcome influenced by HPV status.

\section{Diagnostic technique}

Histopathology and immunohistochemistry. All histopathological diagnoses and immunohistochemical interpretations were made by consultant head and neck histopathologists. Immunohistochemistry (streptavidin-biotin peroxidise complex method, with diaminobenzidine as the chromogen) was performed on $4-\mu \mathrm{m}$ sections of formalin-fixed, paraffin-embedded tissue for p16 (which is considered a surrogate marker for HPV infection), using p16 antibody (in prediluted form; Roche Diagnostics Ltd., Burgess Hill, $\mathrm{UK}$ ), with appropriate positive and negative controls. The sections were counterstained with haematoxylin. Diffuse strong nuclear expression of $\geqslant 70 \%$ of tumour nuclei for p16 was considered positive.

\section{Treatment}

Chemotherapy schedule. All patients, aged 70 years and under with Stages III and IV disease received induction chemotherapy: two cycles of cisplatin $\left(75 \mathrm{mg} \mathrm{m}^{-2}\right)$ day 1 and 5-fluorouracil (5-FU) (1000 $\mathrm{mg} \mathrm{m}^{-2}$ ) days $1-4$ on a 21 day cycle (Bhide et al, 2008). Patients received cisplatin $100 \mathrm{mg} \mathrm{m}^{-2}$ on days 1 and 29 of IMRT. Where cisplatin was contra-indicated (impaired renal function, creatinine clearance $<50 \mathrm{ml} \mathrm{min}^{-1}$, ototoxicity or neuropathy) carboplatin (AUC5) was administered (Wilkins et al, 2013). Weekly cetuximab was administered in patients who on clinical review were unsuitable for platinum-based chemotherapy. A small cohort had also undergone surgery as their primary treatment and therefore did not receive induction chemotherapy and received post-operative chemoradiation.

Patients referred from other institutions had received induction chemotherapy as per their local guidelines; following publication of Vermorken et al and Posner et al this included docetaxel $\left(75 \mathrm{mg} \mathrm{m}^{-2}\right)$, cisplatin $\left(75 \mathrm{mg} \mathrm{m}^{-2}\right)$ and 5-fluorouracil $\left(1000 \mathrm{mg} \mathrm{m}^{-2}\right.$ ) days $1-4$ on a 21 day cycle (Posner et al, 2007; Vermorken et al, 2007).

Radiotherapy technique. Patients were immobilised using a custom-made mask. Target volumes and organs at risk (brainstem, spinal cord and parotid glands) were delineated by following ICRU-50 and -62 guidelines. The planning target volume 1 (PTV1) comprised the primary site, bilateral parapharyngeal spaces and lymph node levels with macroscopic disease to receive $65 \mathrm{~Gy}$ in 30 daily fractions (Fx); PTV2, elective lymph node levels $(54 \mathrm{~Gy} / 30 \mathrm{Fx})$ and PTV3 post-operative lymph node levels (60 Gy/30Fx).

Radiotherapy was delivered using five- or seven-beam simultaneous integrated boost IMRT technique. Radiation dose was prescribed to the median of the PTV1 dose volume histogram, such that $50 \%$ of the volume received the prescription dose and $95 \%$ of each PTV was encompassed by $95 \%$ of the prescription dose with maximum doses to the spinal cord and brainstem being $46 \mathrm{~Gy}$ and $54 \mathrm{~Gy}$, respectively. Primarily a higher planning objective mean dose to the combined superficial lobes of both parotid glands receiving a mean dose $24 \mathrm{~Gy}$ was applied and secondary objective of contralateral parotid gland $<24 \mathrm{~Gy}$. The contralateral parotid gland was described in relation to the location of the primary site 
of disease. Parotid tissue lateral to the retromandibular vein was defined as the superficial lobe. The superficial lobes of each parotid gland were combined as a single structure.

Outcome assessment. Complete response (CR) was defined as complete disappearance of disease as evaluated clinically including nasoendoscopy and CT. RECIST criteria were used to record radiological response. Where residual lesions were present in the oropharynx, hypopharynx or neck, biopsies or fine needle aspirations were performed to determine the presence of persistent disease. Neck dissection was undertaken if patients demonstrated a clinical or radiological partial response (PR), stable disease or PD after radiotherapy. Recurrence was defined as clinical, radiological and/or histopathological evidence of disease presenting three months after completing radiotherapy. Where possible, patients proceeded to salvage surgery for persistent or recurrent disease.

Acute toxicity scores were recorded using NCI-CTCAE v3.0 weekly during chemo-IMRT, for 4 weeks of recovery and at week 14. Indications for enteral feeding were: weight loss $>10 \%$, risk of aspiration and inability to maintain adequate calorific intake (DCTD, NCI, NIH, DHHS, 2003). Late toxicity scores (RTOG/ EORTC and LENTSOMA) were recorded at follow-up at 3, 6, 12, 18 and 24 months after radiotherapy (Rubin et al, 1995).

Statistical analysis. The incidence of an acute or late toxicity was defined as the total number of patients reaching that grade at any time, divided by the total number of assessable patients (Bentzen et al, 2001). Outcome measures following chemo-IMRT were described by local (at primary site) and regional (neck) control. Loco-regional control rate was defined as the proportion of patients with no evidence of recurrent local and/or neck disease. Loco-regional progression-free survival was calculated as the time from the diagnosis to recurrent local and/or nodal disease. Patients with persistent disease at primary site or neck were included as loco-regional events. Progression-free survival was defined as the time from diagnosis to the development of loco-regional and/or distant disease. Overall survival was measured from diagnosis to death from any cause. Survival analyses were estimated using the Kaplan-Meier method. Two-year LRPFS, PFS and OS rates were compared between HPV-positive and HPV-negative patients applying the log rank test.

\section{RESULTS}

Patient characteristics and treatment compliance. From December 2005 to May 2010, 120 patients were enrolled into the study. Median follow-up was 49.9 months (range: 3.3-97.6). Table 1 lists the pre-treatment demographics and tumour characteristics. Oropharyngeal cancers were the dominant primary site (94\%) with 102 patients $(87 \%)$ receiving primary chemoradiation or primary radiation alone. Seventy-three percent of patients received induction chemotherapy and $85 \%$ received concomitant chemotherapy (including cetuximab). Thirteen patients underwent primary surgery presented with oropharyngeal tumour (tonsil or base of tongue) and nodal disease. These cases on final pathology review demonstrated at least $\mathrm{R} 1$ resection and/or nodal disease at multiple levels with or without extracapsular spread, hence recommendation for post-operative chemoradiotherapy. One hundred and nineteen patients completed radiotherapy; one patient reported grade 3 mucositis and did not complete treatment and stopped at $52.1 \mathrm{~Gy}$. The patient continues to be disease free. HPV status was reported in 99 patients $(83 \%)$ and positive in 73 patients (61\%) of all cases. Of the HPV-negative cohort, $73 \%$ reported a smoking history.

Mean dose to parotid glands. The median mean dose to the combined superficial lobes parotid glands was 26.9 Gy (range:
Table 1. Patient characteristics

\begin{tabular}{|c|c|}
\hline Characteristic & $N=120(\%)$ \\
\hline $\begin{array}{l}\text { Median follow-up } \\
\text { (range) } \\
\text { Median age } \\
\text { (range) }\end{array}$ & $\begin{array}{l}49.9 \text { months } \\
(3.3-97.6) \\
57 \text { years } \\
(33-80)\end{array}$ \\
\hline \multicolumn{2}{|l|}{ Sex } \\
\hline $\begin{array}{l}\text { Female } \\
\text { Male }\end{array}$ & $\begin{array}{l}29(24) \\
91(76)\end{array}$ \\
\hline \multicolumn{2}{|l|}{ Performance status } \\
\hline $\begin{array}{l}0 \\
1\end{array}$ & $\begin{array}{c}2(2) \\
118(98)\end{array}$ \\
\hline \multicolumn{2}{|l|}{ HPV status } \\
\hline $\begin{array}{l}\text { Positive } \\
\text { Negative } \\
\text { Unknown }\end{array}$ & $\begin{array}{l}74(62) \\
26(22) \\
20(16)\end{array}$ \\
\hline \multicolumn{2}{|l|}{ Tumour site } \\
\hline $\begin{array}{l}\text { Oropharynx } \\
\text { Hypopharynx }\end{array}$ & $\begin{array}{c}110(92) \\
10(8)\end{array}$ \\
\hline \multicolumn{2}{|l|}{ T stage } \\
\hline $\begin{array}{l}\text { T1 } \\
\text { T2 } \\
\text { T3 } \\
\text { T4 }\end{array}$ & $\begin{array}{l}25 \\
51 \\
23 \\
21\end{array}$ \\
\hline \multicolumn{2}{|l|}{ N stage } \\
\hline $\begin{array}{l}\text { N0 } \\
\text { N1 } \\
\text { N2a } \\
\text { N2b } \\
\text { N2c } \\
\text { N3 }\end{array}$ & $\begin{array}{c}23 \\
17 \\
10 \\
46 \\
22 \\
2\end{array}$ \\
\hline \multicolumn{2}{|l|}{ AJCC stage } \\
\hline $\begin{array}{l}\text { I } \\
\text { II } \\
\text { III } \\
\text { IVa } \\
\mathrm{IVb}\end{array}$ & $\begin{aligned} & 1(1) \\
& 10(8) \\
& 19(16) \\
& 88(73) \\
& 2(2)\end{aligned}$ \\
\hline \multicolumn{2}{|l|}{ Induction chemotherapy } \\
\hline $\begin{array}{l}\text { Cisplatin }+5 \text {-Flurouracil (PF) } \\
\text { Carboplatin }+5 \text {-Flurouracil (Carbo-F) } \\
1 \mathrm{PF}+1 \text { Carbo-F } \\
1 \mathrm{PF} \text { or } 1 \text { Carbo-F } \\
\text { Docetaxel }+ \text { Cisplatin }+5 \text {-Flurouracil }\end{array}$ & $\begin{aligned} 69 & (58) \\
7 & (6) \\
5 & (4) \\
2 & (2) \\
3 & (3)\end{aligned}$ \\
\hline \multicolumn{2}{|l|}{ Concomitant chemotherapy } \\
\hline $\begin{array}{l}\text { Cisplatin (P) } \\
\text { Carboplatin (carbo) } \\
1 \mathrm{P}+1 \text { Carbo } \\
\text { Cetuximab }\end{array}$ & $\begin{array}{l}65(54) \\
20(17) \\
14(12) \\
2(2)\end{array}$ \\
\hline \multicolumn{2}{|l|}{ Radiotherapy } \\
\hline $\begin{array}{l}\text { Primary } \\
\text { Postoperative }\end{array}$ & $\begin{array}{r}103(87) \\
17(13) \\
\end{array}$ \\
\hline
\end{tabular}

16.8-41.9 Gy), the median mean dose to contralateral and ipsilateral whole parotid gland was 31.4Gy (19.6-44.6) and 38.3 Gy (25.2-61.5), respectively.

Compliance to systemic therapy. Sixty nine patients (58\%) completed two cycles cisplatin and 5-fluorouracil (PF), 7 (6\%) completed two cycles carboplatin and 5-fluorouracil (carbo-F), five patients completed one PF and one carbo-F. Two patients (2\%) completed one cycle of PF or carbo-F. Three patients completed induction docetaxel, cisplatin and 5-fluorouracil (TPF) (two received three cycles, one received four cycles).

Sixty-five patients (54\%) completed two cycles concomitant cisplatin, 20 patients (17\%) completed two cycles carboplatin, 
14 patients received one cycle cisplatin, changed to carboplatin for the second cycle secondary to renal impairment and ototoxicity. Two patients received concomitant cetuximab.

Acute toxicity. Acute toxicities peaked at week 6 of radiotherapy and are summarised in Table 2 and Figure 1. Grade 4 dermatitis was reported in two patients, both received concomitant cetuximab; no other grade 4 toxicities were reported. The majority of high-grade ( $\geqslant$ grade 2 ): mucositis $(86 \%)$, dysphagia $(75 \%)$, fatigue $(64 \%)$, subjective xerostomia $(65 \%)$ and pain $(83 \%)$ peaked at the end of radiotherapy and recovered by 2 months after radiotherapy. There was no difference in the incidence of xerostomia between HPV-negative (65\%) and HPV-positive $(62 \%)$ cases. Nine percent of patients reported grade 3 dysphagia and $35 \%$ reported grade 2 xerostomia at 2 months after radiotherapy (33\% HPV-negative and 35\% HPV-positive).

Late toxicity. A total 84 patients were assessable at 12 months for toxicity assessment of which, 69 patients with HPV status were assessable at 12 months. The incidence of high-grade subjective xerostomia at 12 months was $23 \%$ in all cases and $21 \%$ with available HPV status. The incidence of high-grade subjective xerostomia was $16 \%$ at 24 months. Thirty-three percent (4 of 12) HPV-negative patients reported high-grade subjective xerostomia compared with $18 \%$ (10 of 57) HPV-positive patients. No patient reported grade 3 dysphagia. Seven percent were recorded to have grade 2 ototoxicity and $1 \%$ grade 2 dyspahgia. Toxicities are summarised in Table 3.

Xerostomia. A high incidence of subjective xerostomia was reported on the completion of radiotherapy, $65 \%$ reported $\geqslant$ grade 2 xerostomia. Two months after completing radiotherapy, $35 \%$ patients reported high-grade subjective xerostomia recovering to $21 \%$ at 12 months after radiotherapy.
Treatment outcomes. At 3 months after completing treatment, 110 patients $(76 \%)$ who received primary treatment demonstrated a CR at the primary site. Eight-six patients presented with lymph node metastases of which 72 (84\%) demonstrated a CR and 16\% a PR. Nine patients demonstrated loco-regional relapse, within the high dose volume and further nine patients developed distant metastatic disease. Twenty-two patients died with cause of death classified as non-cancer related in seven cases. For all cases, 2 year loco-regional PFS was $90.7 \%$ (95\% CI: 85.2-96.2). According to HPV status, there was a significant difference for 2 year locoregional PFS, 76.8\% (52.0-90.0) (HPV-negative) vs 98.6\% (90.599.8) (HPV-positive), $P=0.001$. HPV-positive patients also demonstrated a superior PFS and OScompared with HPV-negative patients (Figures 2 and 3). Specifically, on evaluating patients who received who received primary induction chemotherapy and chemoradiotherapy, 2-year OS was 90.0\% (82.4-97.6) for HPVpositive cases and 64.7\% (36.7-85.7) HPV-negative, $P<0.001$, with 2-year PFS and loco-regional PFS higher in HPV-positive patients 90.0 vs $51.3 \%, P<0.001$ (see Figures 4 and 5).

\section{DISCUSSION}

Induction chemotherapy and chemo-IMRT in the treatment of midline HNSCC is feasible with minimal long-term morbidity. Seventy-three percent of patients received induction chemotherapy and $85 \%$ received concomitant chemotherapy. The remainder were either greater than 70 years of age and/or receiving post-operative chemoradiotherapy. Carbplatin was recommended where cisplatin was contra-indicated, as previous matched-pair analysis had reported carboplatin-based chemoradiotherapy demonstrated equivalent treatment outcomes. Two patients received weekly

\section{Table 2. Frequency of acute toxicity (CTCAE v3.0)}

\begin{tabular}{|c|c|c|c|c|c|c|c|c|c|c|}
\hline \multicolumn{11}{|c|}{ Frequency (\%) } \\
\hline Acute toxicity at end of RT (grey) and 2 months after RT (white) & GO & G0 & G1 & G1 & G2 & G2 & G3 & G3 & G4 & G4 \\
\hline Dermatitis & 3 & 84 & 42 & 16 & 51 & 0 & 3 & 0 & 1 & 0 \\
\hline Mucositis & 1 & 48 & 13 & 41 & 47 & 11 & 39 & 0 & 0 & 0 \\
\hline Dysphagia-pharyngeal & 3 & 42 & 22 & 32 & 36 & 17 & 39 & 9 & 0 & 0 \\
\hline Dysphagia-oesophageal & 52 & 67 & 7 & 16 & 18 & 11 & 23 & 6 & 0 & 0 \\
\hline Fatigue & 3 & 25 & 33 & 64 & 54 & 9 & 10 & 2 & 0 & 0 \\
\hline Pain & 3 & 50 & 14 & 45 & 57 & 5 & 26 & 0 & 0 & 0 \\
\hline Ototoxicity & 95 & 73 & 3 & 17 & 2 & 10 & 0 & 0 & 0 & 0 \\
\hline Xerostomia & 0 & 13 & 35 & 52 & 63 & 35 & 2 & 0 & 0 & 0 \\
\hline Weight & 40 & 19 & 39 & 20 & 21 & 61 & 0 & 0 & 0 & 0 \\
\hline
\end{tabular}

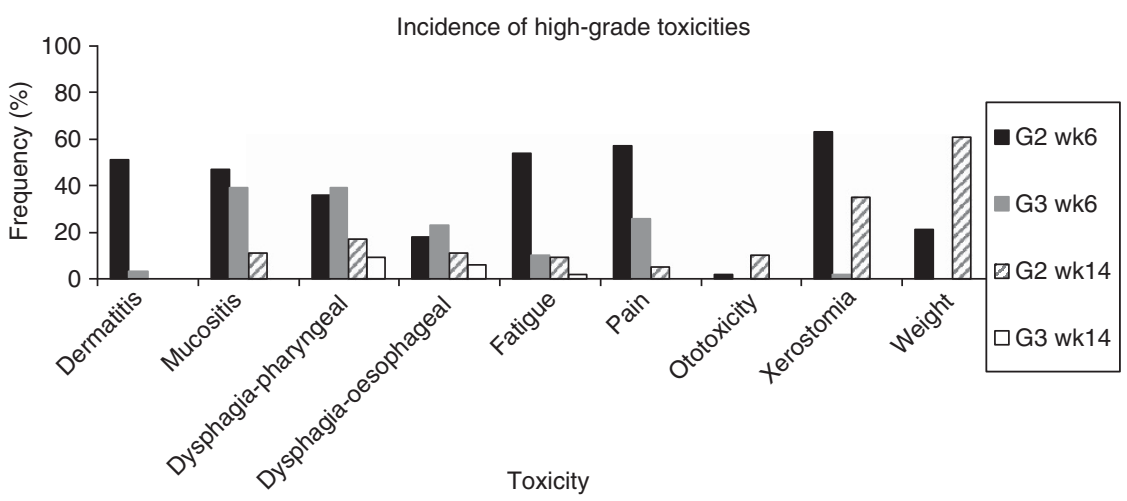

Figure 1. Incidence of high-grade acute toxicity at the end of radiotherapy (wk 6) and 2 months after radiotherapy (wk14). 
Table 3. Type and frequency of late radiotherapy adverse effects (LENTSOMA) at 1 year

\begin{tabular}{|l|c|c|c|c|c|}
\hline Late toxicity & G0 & G1 & G2 & G3 & G4 \\
\hline Skin & 88 & 12 & 0 & 0 & 0 \\
\hline Subcutaneous tissue & 84 & 16 & 0 & 0 & 0 \\
\hline Mucosa & 98 & 2 & 0 & 0 & 0 \\
\hline Pharynx/dysphagia & 86 & 13 & 1 & 0 & 0 \\
\hline Ototoxicity & 78 & 14 & 7 & 1 & 0 \\
\hline Subjective xerostomia & 24 & 55 & 21 & 0 & 0 \\
\hline Objective xerostomia & 34 & 57 & 9 & 0 & 0 \\
\hline Oesophagus & 90 & 8 & 0 & 2 & 0 \\
\hline Larynx & 88 & 10 & 2 & 0 & 0 \\
\hline Spinal cord & 100 & 0 & 0 & 0 & 0 \\
\hline
\end{tabular}

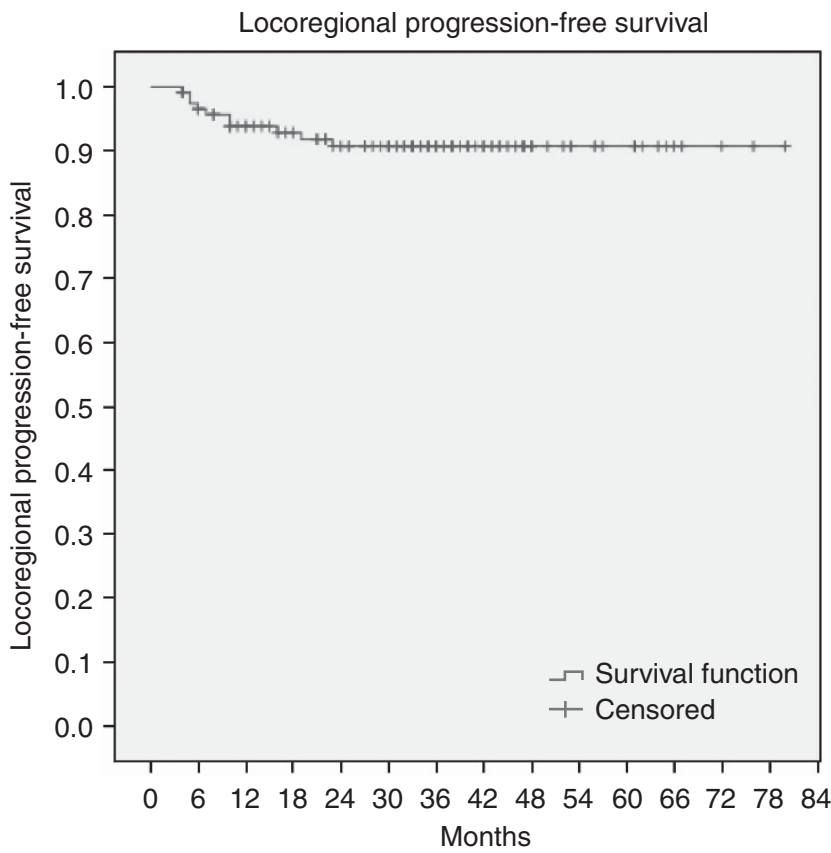

Figure 2. Loco-regional progression-free survival for all cases, 2-year LRPFS: $90.7 \%$ (95\% Cl: 85.2-96.2).

cetuximab on clinical discretion as the preferred treatment because of the contra-indications to platinum-based chemotherapy and multiple co-morbidities.

Bilateral superficial lobe parotid-sparing IMRT resulted in a lower incidence of long-term subjective xerostomia when compared with contralateral parotid-sparing IMRT in the PARSPORT trial. This study reports a lower incidence of high-grade subjective xerostomia (38 vs 23\%) despite a higher dose to the contralateral parotid gland, $31.4 \mathrm{~Gy}$ in this study compared with the PARSPORT trial (25.4 Gy) (Nutting et al, 2011). At 24 months, continued improvement was seen in this study compared with the PARSPORT trial (16 vs 29\%). Further to this, the HPV-positive cohort reported an $18 \%$ incidence of high-grade xerostomia at 12 months. Also there was no additional toxicity from concomitant chemotherapy in this study (Miah et al, 2013a). This study has demonstrated that bilateral superficial lobe parotid-sparing IMRT can minimise long-term xerostomia. We hypothesise that the superficial lobe of the parotid gland may be more important in regaining salivary gland secretion or that possibly the technique

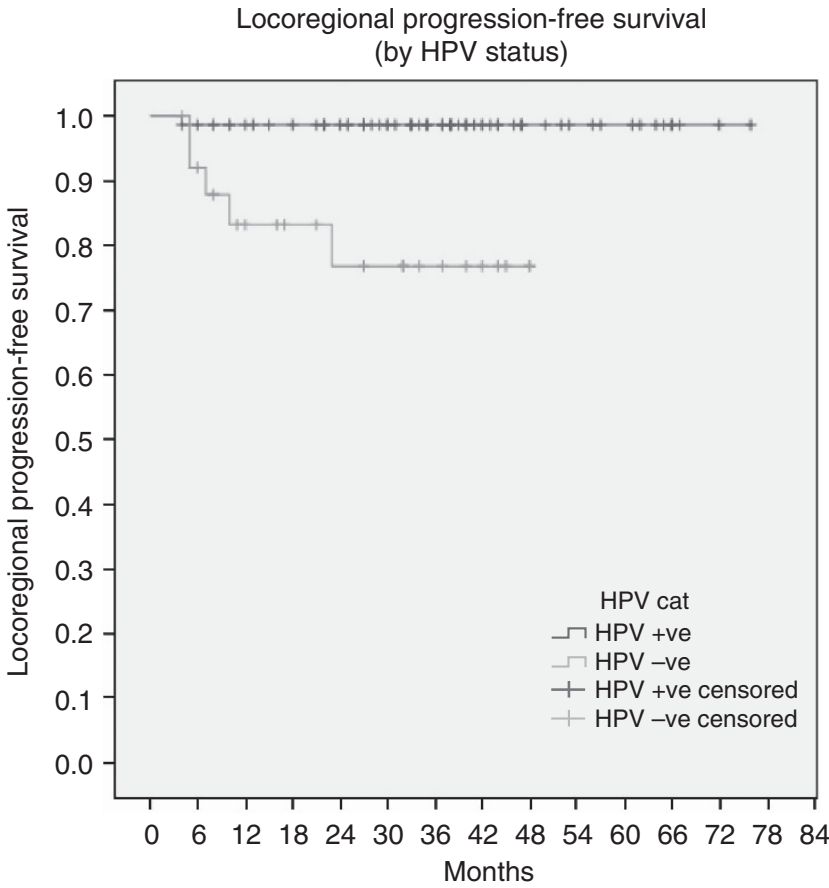

Figure 3. Loco-regional progression-free survival for HPV-positive (74 patients) and HPV-negative (26 patients), 2-year LRPFS: 98.6 (95\% Cl: 90.5-99.8) and 76.8\% (95\% Cl: 52.0-90.0), $P=0.001$.

spares the parotid gland stem cell region allowing better recovery of gland function. The comparison with data from the PARSPORT trial is not optimal. There are significant limitations in attempting a matched-pair analysis with this data, the sample size for comparison would be very small. The PARSPORT trial only reported on 42 patients in the parotid-sparing arm. In addition, objective measures of xerostomia and quality of life have not been reported and as only a very small proportion of patients reported this additional information which did not represent the study population. Xerostomia symptoms are multifactorial, not only influenced by parotid gland function but also potentially other salivary gland function. Miah et al (2013b) previously reported subjective xerostomia to show a strong association with parotid gland tolerance dose, salivary flow rates and xerostomia-related quality of life therefore recommended the use of subjective xerostomia as the best representative measure because of the ease of recording this score.

In this study, 2-year loco-regional PFS is reported at $85 \%$ but with very high control rates in the HPV-positive cohort (98.6\%). This also translates to a higher OS $93 \%$ at 2 years. Previously, Bhide et al reported local control, disease-specific survival and OS in locally advanced HNSCC at 2 years were 71, 68 and 63\%, respectively (Bhide et al, 2008). This is comparable to the HPVnegative cohort reported in this study. When compared with the survival outcomes for HPV-positive and HPV-negative cases reported in the RTOG 0129, our study reported similar outcomes and differences associated with HPV status (Ang et al, 2010). The majority of patients received doublet induction chemotherapy rather than TPF in combination. This perhaps highlights the limited additional benefits in TPF in HPV-positive patients and that platinum and 5-fluorouracil alone may be sufficient as induction therapy in this cohort or whether induction chemotherapy can be avoided completely. However, recently Hitt et al (2014) reported on the efficacy of 3 cycles of induction chemotherapy (TPF vs PF) followed by chemoradiation with cisplatin at $100 \mathrm{mg} \mathrm{m}^{-2}$ days 1,22 and 43 or chemoradiation alone in locally advanced unresectable HNSCC. This study failed to demonstrate 


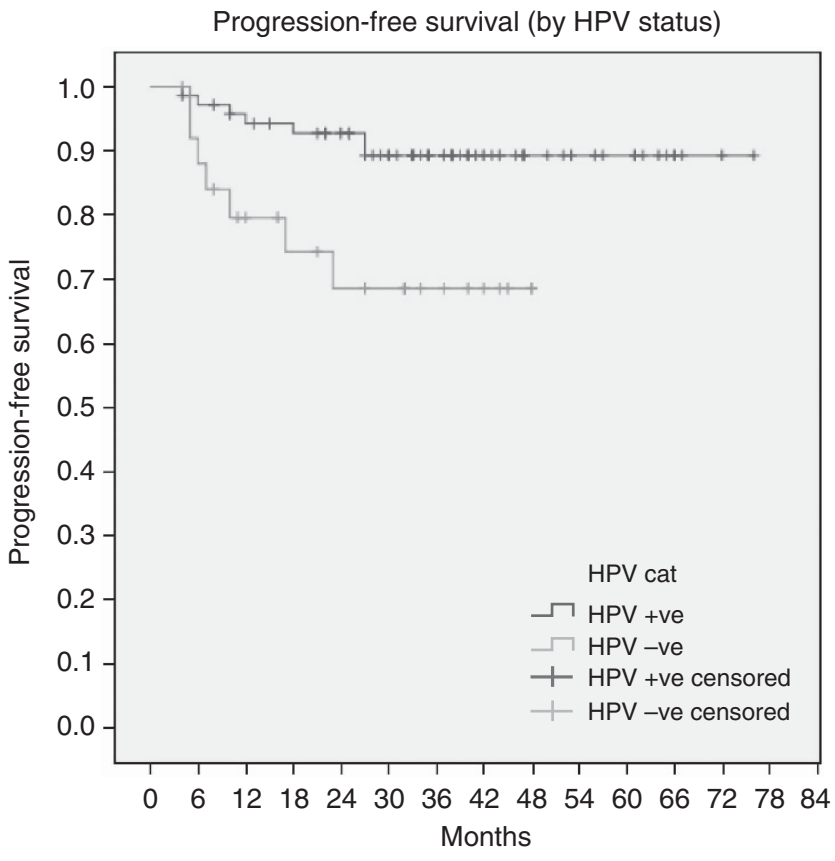

Figure 4. Progression-free survival for HPV-positive (74 patients) and HPV-negative (26 patients), 2-year PFS: 93.0 (95\% Cl: 83.4-96.9) and $69.0 \%$ (95\% Cl: 44.4-83.9), $P=0.012$.

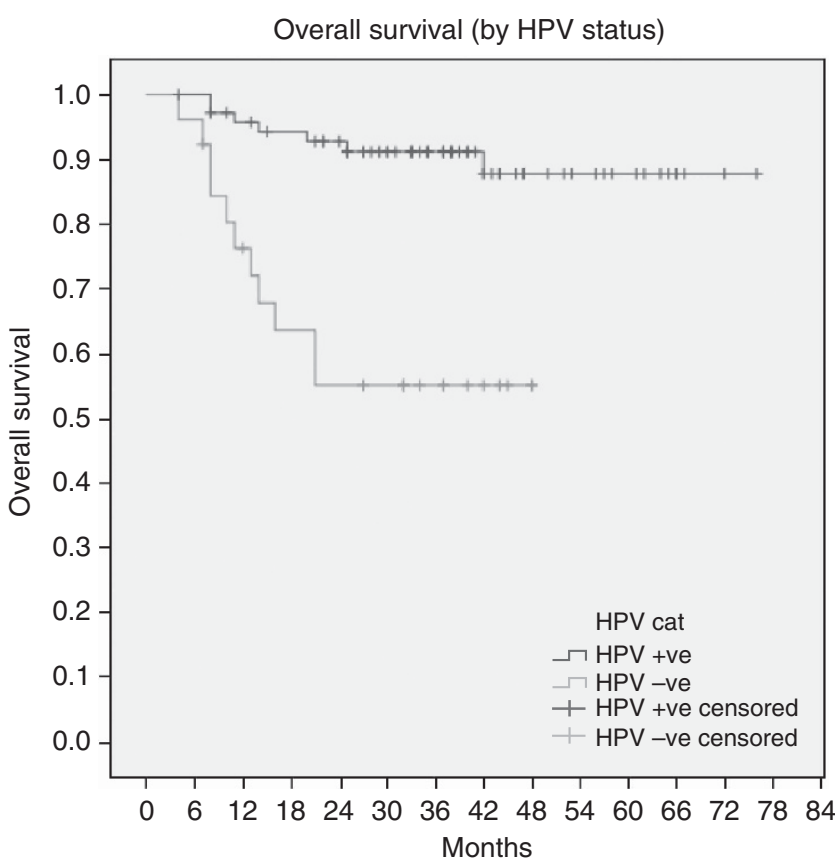

Figure 5. Overall survival for HPV-positive (74 patients) and HPVnegative (26 patients), 2-year OS: 93.0 (95\% Cl: 83.5-96.9) and $52.0 \%$ (95\% Cl: 33.6-72.2), $P<0.001$.

any survival advantage of induction chemotherapy (TPF or PF) compared with chemoradiation alone. Patients were matched according to stage and primary site but HPV status was unknown in this study and could potentially have been a confounding factor. HPV-positive oropharyngeal squmaous cell cancers are continuing to increase in incidence and are classified as a specific disease entity with an excellent prognosis. It is therefore essential to deliver the optimal treatment but minimise acute and long-term morbidity. In this study $18 \%$ of HPV-positive patients reported high-grade xerostomia at 12 months, providing further support to apply the superficial lobe parotid-sparing technique for patients who will live a long-time with residual toxicity The CRUK DE-ESCALATE study hopes to answer the question whether concomitant cetuximab can provide less morbidity compared with concomitant cisplatin (3 cycles) with similar survival outcomes. HPV-positive HNSCC responds better to radiation therapy but there is little evidence for increased radiosensitivity to justify lowering total radiation dose in this cohort of patients at the current time. In this study, one patient received a total dose of $52.1 \mathrm{~Gy}$ in 24 daily fractions due to grade 3 mucositis with a CR and disease free at 2 years.

However, we must also highlight the inferior outcomes in the HPV-negative cohort. Indeed, 2-year loco-regional control approaches $80 \%$, with PFS at $69 \%$ but 2 -year OS dramatically falls to $53 \%$. The dismal outcomes in this cohort of patients may be partly explained by the confounding factors of the causative agents of tobacco smoking and excess alcohol consumption and their associated co-morbidities. In our study, $73 \%$ of HPV-negative patients reported a current or previous smoking history and seven patients died from non-head and neck cancer related illness. Could dose-escalation strategies and intensive chemotherapy schedules possibly compensate for potentially less radiosensitive disease entity? In addition, therapies targeting HPV-negative driven HNSCC need to be defined and tested. Investigating the mechanism of resistance of epidermal growth factor receptor inhibition in HPV-negative HNSCC may help to identify novel therapies (Lee et al, 2005).

This study has demonstrated an IMRT technique which can further reduce xerostomia, a significant toxicity noted to impact on overall quality of life. In addition, different disease entities have been described to demonstrate the need to manage HPV-positive disease differently from HPV-negative disease. We await the outcome of DE-ESCALATE to provide guidance.

\section{CONCLUSIONS}

This is the largest UK prospective series of midline HNSCC treated with induction chemotherapy and concomitant chemo-IMRT demonstrating excellent survival outcomes and a low incidence of long-term morbidity. Two-year survival outcomes differ significantly between HPV-positive and HPV-negative disease, potentially considering different treatment schedules for the different disease entities which could be evaluated in future clinical trials. The bilateral superficial lobe parotid-sparing IMRT technique has demonstrated a low incidence of high-grade subjective xerostomia.

\section{ACKNOWLEDGEMENTS}

This analysis was funded by Cancer Research UK, Section of Radiotherapy Grant number C46/A2131 and Head and Neck Program Grant number C7224/A13407. We acknowledge NHS funding to the NIHR Biomedical Research Centre.

\section{REFERENCES}

Ang KK, Harris J, Wheeler R, Weber R, Rosenthal DI, Nguyen-Tân PF, Westra WH, Chung CH, Jordan RC, Lu C, Kim H, Axelrod R, Silverman CC, Redmond KP, Gillison ML. (2010) Human papillomavirus and survival of patients with oropharyngeal cancer. N Engl J Med 363: 24-35.

Bentzen SM, Saunders MI, Dische S, Bond SJ (2001) Radiotherapy-related early morbidity in head and neck cancer: quantitative clinical radiobiology as deduced from the CHART trial. Radiother Oncol 60: 123-135.

Bhide SA, Ahmed M, Barbachano Y, Newbold K, Harrington KJ, Nutting CM (2008) Sequential induction chemotherapy followed by radical 
chemo-radiation in the treatment of locoregionally advanced head-andneck cancer. Br J Cancer 99: 57-62.

DCTD, NCI, NIH, DHHS (2003) Cancer Therapy Evaluation Program. Common terminology criteria for adverse events v3.0. http://ctep.cancer. gov/protocolDevelopment/electronic_applications/docs/ctcaev3.pdf.

Gillison ML (2004) Human papillomavirus-associated head and neck cancer is a distinct epidemiologic, clinical, and molecular entity. Semin Oncol 31: 744-754.

Hitt R, Grau JJ, López-Pousa A, Berrocal A, García-Girón C, Irigoyen A, Sastre J, Martínez-Trufero J, Brandariz Castelo JA, Verger E, Cruz-Hernández JJ. Spanish Head and Neck Cancer Cooperative Group (TTCC) (2014) A randomized phase III trial comparing induction chemotherapy followed by chemoradiotherapy versus chemoradiotherapy alone as treatment of unresectable head and neck cancer. Ann Oncol 25: 216-225.

Lee JW, Soung YH, Kim SY, Nam HK, Park WS, Nam SW, Kim MS, Sun DI, Lee YS, Jang JJ, Lee JY, Yoo NJ, Lee SH (2005) Somatic mutations of EGFR gene in squamous cell carcinoma of the head and neck. Clin Cancer Res 11: $2879-2882$.

Mehanna H, Paleri V, West CM, Nutting C (2010) Head and neck cancerPart 1: epidemiology, presentation, and prevention. BMJ 341: c4684.

Miah AB, Gulliford SL, Bhide SA, Zaidi SH, Newbold KL, Harrington KJ, Nutting CM (2013a) The effect of concomitant chemotherapy on parotid gland function following head and neck IMRT. Radiother Oncol 106: 346-351.

Miah AB, Gulliford SL, Clark CH, Bhide SA, Zaidi SH, Newbold KL, Harrington KJ, Nutting CM (2013b) Dose-response analysis of parotid gland function: what is the best measure of xerostomia? Radiother Oncol 106: $341-345$.

National Cancer Intelligence Network (2008) Incidence and mortality from head and neck cancers in England 2002-2006.

Nutting CM, Morden JP, Harrington KJ, Urbano TG, Bhide SA, Clark C, Miles EA, Miah AB, Newbold K, Tanay M, Adab F, Jefferies SJ, Scrase C, Yap BK, A'Hern RP, Sydenham MA, Emson M, Hall E. PARSPORT trial management group (2011) Parotid-sparing intensity modulated versus conventional radiotherapy in head and neck cancer (PARSPORT): a phase 3 multicentre randomised controlled trial. Lancet Oncol 12: 127-136.
Patel SG, Shah JP (2005) TNM staging of cancers of the head and neck: striving for uniformity among diversity. CA Cancer J Clin 55: 242-258quiz 261-2, 264.

Posner MR, Hershock DM, Blajman CR, Mickiewicz E, Winquist E, Gorbounova V, Tjulandin S, Shin DM, Cullen K, Ervin TJ, Murphy BA, Raez LE, Cohen RB, Spaulding M, Tishler RB, Roth B, Viroglio Rdel C, Venkatesan V, Romanov I, Agarwala S, Harter KW, Dugan M, Cmelak A, Markoe AM, Read PW, Steinbrenner L, Colevas AD, Norris Jr CM, Haddad RI. TAX 324 Study Group (2007) Cisplatin and fluorouracil alone or with docetaxel in head and neck cancer. N Engl J Med 357: $1705-1715$.

Pow EH, Kwong DL, McMillan AS, Wong MC, Sham JS, Leung LH, Leung WK (2006) Xerostomia and quality of life after intensity-modulated radiotherapy vs. conventional radiotherapy for early-stage nasopharyngeal carcinoma: initial report on a randomized controlled clinical trial. Int J Radiat Oncol Biol Phys 66: 981-991.

Rubin P, Constine 3rd LS, Fajardo LF, Phillips TL, Wasserman TH (1995) EORTC Late Effects Working Group. Overview of late effects normal tissues (LENT) scoring system. Radiother Oncol 35: 9-10.

Vermorken JB, Remenar E, van Herpen C, Gorlia T, Mesia R, Degardin M, Stewart JS, Jelic S, Betka J, Preiss JH, van den Weyngaert D, Awada A, Cupissol D, Kienzer HR, Rey A, Desaunois I, Bernier J, Lefebvre JL. EORTC 24971/TAX 323 Study Group (2007) Cisplatin, fluorouracil, and docetaxel in unresectable head and neck cancer. N Engl J Med 357: 1695-1704.

Wilkins AC, Rosenfelder N, Schick U, Gupta S, Thway K, Nutting CM, Harrington KJ, Newbold K, Bhide SA (2013) Equivalence of cisplatin and carboplatin-based chemoradiation for locally advanced squamous cell carcinoma of the head and neck: a matched-pair analysis. Oral Oncol 49: 615-619.

This work is published under the standard license to publish agreement. After 12 months the work will become freely available and the license terms will switch to a Creative Commons AttributionNonCommercial-Share Alike 3.0 Unported License. 